\title{
Modelling habitat associations of 14 species of holothurians from an unfished coral atoll: implications for fisheries management
}

\author{
L. M. Bellchambers ${ }^{1, *}$, J. J. Meeuwig ${ }^{2}$, S. N. Evans ${ }^{1}$, P. Legendre ${ }^{2,3}$ \\ ${ }^{1}$ Department of Fisheries, Western Australian Fisheries and Marine Research Laboratories, North Beach, \\ Western Australia 6920, Australia
}

${ }^{2}$ The University of Western Australia, School of Animal Biology and Centre for Marine Futures, Oceans Institute, Crawley, Western Australia 6009, Australia

${ }^{3}$ Université de Montréal, Département de Sciences Biologiques, Montréal, Québec H3C 3J7, Canada

\begin{abstract}
Currently there is no commercial or subsistence fishing for holothurians on the Cocos (Keeling) Islands and, despite a prominent government presence, no reported cases of poaching or illegal fishing. However, because of recent interest in developing a commercial fishery for holothurians there, a survey was initiated to provide baseline data on the previously unfished local holothurian populations. Fourteen species of holothurians were recorded during the survey, with the most abundant species being Holothuria atra; only 4 other species had relatively high abundances. A total of 20556 holothurians were counted; however, $97 \%$ of these were considered to be of low commercial value. The high- and medium-value species found in this survey were all in extremely low abundances, with restricted distributions. The distribution and abundance of holothurians was closely linked with benthic habitats, with $48 \%$ of the variation in holothurian populations explained by 13 habitat variables. Several species displayed distinct habitat preferences: H. atra was associated with sand-dominated habitats, Actinopyga mauritiana was associated with relic reefs and soft corals, while Holothuria fuscopunctata and Stichopus herrmanni were both associated with reef flats. The densities recorded in the present study represent the natural abundance and distribution of holothurian populations at this atoll. Given the low numbers of commercially important species, it is highly unlikely that a commercial fishery would be economically viable at the Cocos (Keeling) Islands and it would be more beneficial to maintain the natural holothurian population.
\end{abstract}

KEY WORDS: Holothurians - Habitat associations - Coral reefs · Exploitation - Unfished populations Resale or republication not permitted without written consent of the publisher

\section{INTRODUCTION}

Holothurians play an important ecological role in nutrient cycling and bioturbation processes in marine benthic communities (Uthicke 1999, Skewes et al. 2002, Mangion et al. 2004, Uthicke et al. 2004b, Purcell 2010). Often the productivity of a habitat, particularly in coral reef systems, is a result of carbon fixation and nutrient recycling provided by benthic micro-algae (Uthicke \& Klumpp 1998, Uthicke et al. 2004b). Previous studies have suggested that holothurians contribute to the oxygenation of the upper sediment levels and play a role in bioturbation that, in turn, may increase the productivity of benthic micro-algae (Uthicke \& Klumpp 1998, Uthicke 1999, Uthicke \& Karez 1999, Uthicke et al. 2004b, 2009), providing increased food resources for other species. The ecological consequences of removing holothuri- 
ans by fishing are unknown. However, given they have important functions in their environment, it is likely that removal of these animals may reduce the overall productivity of coral reefs (Uthicke et al. 2004b, Friedman et al. 2010).

Holothurians are often amongst the most valuable resources for small tropical island communities (Kinch et al. 2008, Purcell 2010). Several species are highly prized by subsistence fishers (e.g. Actinoypa mauritiana and Holothuria atra) as a direct food source (Kinch et al. 2008) and by commercial operators (e.g. Holothuria fuscogilva, H. whitmaei [formerly $H$. nobilis] and $H$. scabra) due to the high demand from Asian markets (Conand \& Byrne 1993, Choo 2008, Purcell 2010). Holothurians are susceptible to overfishing, and these fisheries are typically characterised by boom and bust cycles (Conand \& Byrne 1993, Uthicke \& Benzie 2000, Kinch et al. 2008, Uthicke et al. 2009, Anderson et al. 2010), with most fisheries severely overexploited (Conand 2004, Toral-Granda 2006, Friedman et al. 2010, Purcell

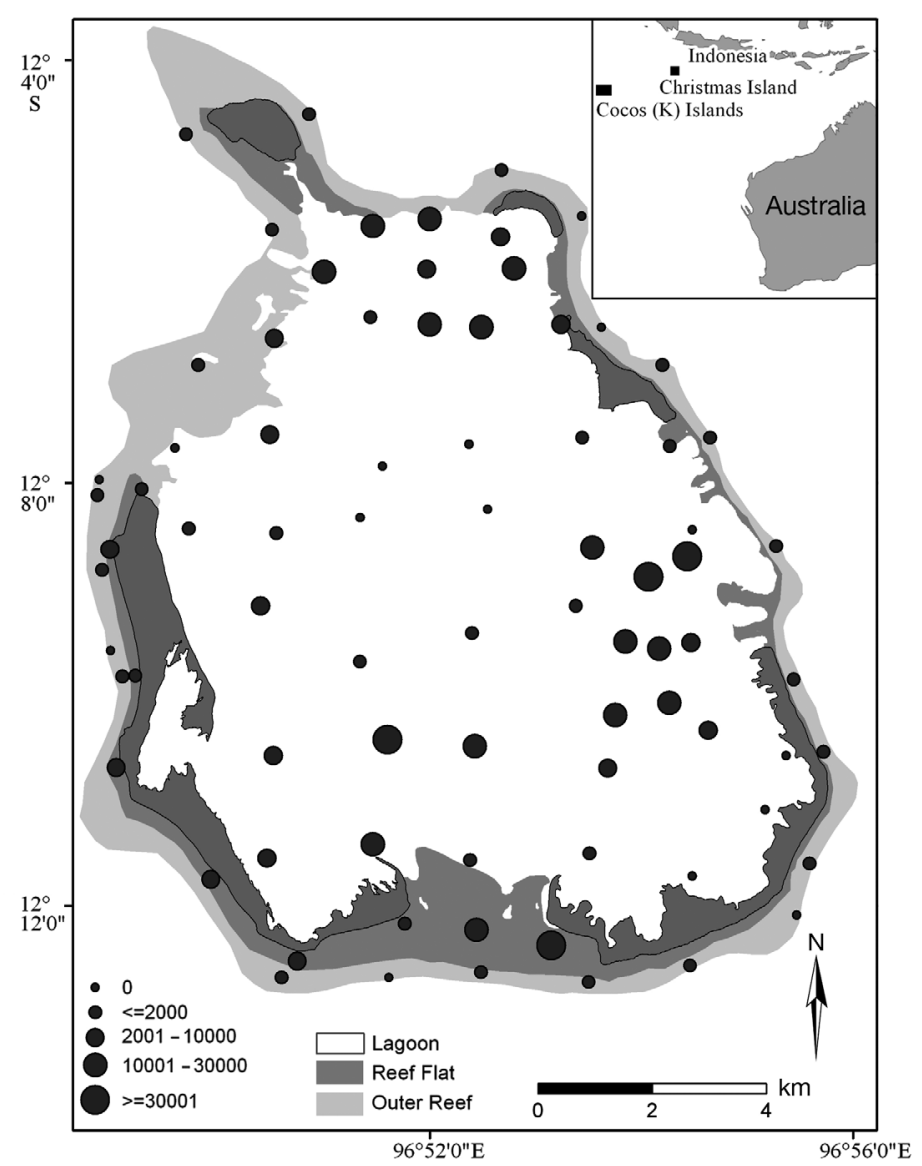

Fig. 1. Location of Cocos (Keeling) Islands (inset), and sampling sites for holothurians around the southern atoll
2010). Conand (2004) identified 42 species under population stress as a result of commercial exploitation. Similarly, an international review of 28 countries found that 21 countries, including Australia, have overexploited holothurian stocks, 5 countries have declining stocks and Malaysia has 1 species close to extinction. Of the 28 countries reviewed, only Cuba has apparently stable stocks (Toral-Granda 2006). Despite the commercial importance of holothurians, their biology, ecology and population dynamics remain poorly understood (Conand 2004, Lovatelli et al. 2004, Friedman et al. 2010). Information on growth rates, larval ecology, recruitment processes, habitat use, their ecological role and fisheries biology is scant and in some cases only available for a few species (Lovatelli et al. 2004, McIlgorm et al. 2007, Friedman et al. 2010, Purcell 2010).

The Cocos (Keeling) Islands are an Australian territory approximately $2800 \mathrm{~km}$ north-west of Perth, Western Australia (Fig. 1). Their shallow marine environment supports a diversity of holothurian species (Gibson-Hill 1949, Lincoln-Smith et al. 1993, Marsh 1994, Hender et al. 2001), although only limited data exist on the distribution and abundance of holothurians there (see Hender et al. 2001). While the local community, composed of traditional Cocos Malays and mainland Australians, relies heavily on the atoll's marine resources for food and recreation, commercial or subsistence harvesting of holothurians does not occur (Hender et al. 2001). The lack of commercial or subsistence harvesting coupled with the small size and isolation of the islands, cultural preferences and beliefs of the resident population and a strong Australian Federal Police (AFP), Australian Quarantine and Inspection Services (AQIS) and Parks Australia presence means that holothurian populations at the Cocos (Keeling) Islands are considered to be unexploited (including both legal and illegal fishing).

The present paper describes a baseline investigation of the abundance and habitat preferences of holothurian species at the Cocos (Keeling) Islands, motivated in part by recent interest in initiating a commercial fishery for holothurians. While the primary aim of fisheries management is ensuring the sustainability of exploited stocks, in recent years increasing emphasis has been placed on broader ecosystem function. A critical step in this process is understanding the relationship between the abundance of organisms and the habitats in which they are found (Freeman \& Rogers 2003, Bellchambers et al. 2010). Previous authors have suggested that the availability and condition of habitats and their con- 
nectivity with nearby reef systems may play a major role in structuring holothurian populations (Kinch et al. 2008). However, the majority of previous studies linking holothurian abundance and distribution and habitat type have focused on populations that have, at some point, been either legally or illegally fished (e.g. Conand \& Chardy 1985, Hammond et al. 1985). The present paper is unique as it describes the abundance and habitat preferences of a diversity of holothurian species in an unexploited state. We model the relationships between holothurian assemblage structure and habitats using distancebased linear regression. Estimates are made of the abundance of holothurians based on their observed numbers and the area of the major habitats with which they are associated. Finally, the potential implications of commercial fishing are considered in light of holothurian abundance and life history.

\section{METHODS}

\section{Study location}

The Cocos (Keeling) Islands are located in the Indian Ocean $\left(12^{\circ} 12^{\prime} \mathrm{S}, 96^{\circ} 54^{\prime} \mathrm{E}\right)$, approximately $2950 \mathrm{~km}$ north west of Perth, $900 \mathrm{~km}$ west-southwest of Christmas Island and $1000 \mathrm{~km}$ southwest of Java Head (Fig. 1) (Bunce 1988). The group is comprised of 2 separate coral atolls, consisting of 27 islands covering a total area of approximately $14 \mathrm{~km}^{2}$. The southern atoll, the focus of the present study, consists of 26 islands surrounding a shallow lagoon, 2 of which are inhabited with a total population of approximately 600 people. The Islands have 3 main aquatic habitat types: the outer reef slope (sub-tidal); reef flats, including sandy and rocky shores (predominantly intertidal); and a lagoon (predominantly subtidal) (Berry 1989).

\section{Survey methodology}

A 4-person team undertook field surveys of holothurian densities between 7 and 24 May 2006. The study was limited to depths of $<29 \mathrm{~m}$ and covered all habitats; intertidal reef flats, shallow lagoon habitats and the outer reef slopes. Sampling was conducted systematically across the entire atoll by dividing the atoll into 1 minute blocks (Hender et al. 2001). A site was then randomly selected within each minute block. This equated to a sampling density of 1 site per $1.8 \mathrm{~km}^{2}$. Our study sites also included sites previously surveyed by Berry (1989) and Hender et al. (2001). Direct comparisons with previous studies were often not possible as the data were either qualitative (Berry 1989) or holothurians were not the primary target of the surveys (Hender et al. 2001). Similarly, survey techniques and intensity were not directly comparable; however, where they were possible, comparisons have been made. During the current study a total of 79 sites were sampled (Fig. 1).

This survey used similar rapid assessment techniques to those used in holothurian surveys at Warrior Reef, Torres Strait (Skewes et al. 1998), Timor Sea MOU Box (Skewes et al. 1999) and Milne Bay Province, PNG (Skewes et al. 2002). Either SCUBA, snorkelling, or reef walks were used, depending on the water depth at each site. Sites were located using a hand-held GPS; once located 2 divers entered the water and swam adjacent $100 \mathrm{~m} \times 4 \mathrm{~m}$ belt transects, spaced $10 \mathrm{~m}$ apart, on a predetermined bearing. Every $10 \mathrm{~m}$ along the transect the abundance of holothurian species was recorded and a visual assessment was made of the percentage cover of the dominate substrate and habitat types.

Paired $t$-tests indicated that there were no significant differences between the observations on the 2 replicate transects at each site, so the abundance of holothurian species and percentage cover of each habitat were averaged across the 2 transects to give the overall density of each holothurian species and the average habitat percentage cover for each site.

\section{Habitat categories}

In the present study habitat is categorised in 2 different ways: fine and broad scale. The fine-scale habitat data were collected during the current survey, using the methods described above; these data were used for the modelling component of the study. The fine-scale habitat categories used in the current study are: sand, rubble (limestone rubble), seagrass, macroalgae, massive coral (corals that are solid and similar in shape in all directions), sub-massive coral (corals less than, or not quite, solid and similar in shape in all directions), plate coral (or laminar, forming a tier), foliose coral (forming a whorl), soft coral (coral without exoskeleton), branching coral (forms with branches), branching coral dead, reef flat (limestone platform) and relict reef (old eroded limestone reef). Fine-scale habitat categories were based on those used by previous studies so comparisons could be made (i.e. Williams 1994, Hender et al. 2001). However, for estimates of holothurian standing bio- 
mass habitat categories that could be quantified across the entire lagoon were required. Therefore, each of the sites surveyed during the current study was also allocated a broad-scale habitat category, adapted from Williams (1994), to estimate the standing biomass of holothurians (see 'Results').

\section{Statistical analysis}

Permutational distance-based approaches were used to examine spatial patterns in holothurian assemblages, as the data were highly skewed and contained many zeros (Clarke \& Warwick 2001). The data were transformed using $\log 10(x+1)$ to reflect the distributions of rare species (only 4 of the 14 species were reasonably common), and the BrayCurtis dissimilarities were calculated. The relationships between holothurian abundances and finescale habitat variables were analysed using distance-based linear models (DISTLM; Legendre \& Anderson 1999, McArdle \& Anderson 2001) in the computer program PRIMER-E+. Forward selection based on all habitat variables was chosen, and Akaike's information criterion was used as a measure of goodness-of-fit. The most parsimonious model was chosen, and the DISTLM analysis then repeated using only those habitat variables selected for this model. A distance-based redundancy analysis (dbRDA) was included to quantify the associations between habitats and the orthogonal axes generated by the dbRDA. Sites were then qualitatively grouped according to the relationship to the first and second dbRDA axes. The SIMPER routine was used to determine which holothurians characterised the groups derived from the dbRDA.

Standing biomass was estimated by calculating the average density of holothurians per $400 \mathrm{~m}^{2}$, for each broad-scale habitat type (from Williams 1994), converting individuals per hectar and then multiplying by the hectares of each habitat type. This was done for all holothurians and then for each economic category (high, medium, low, unknown; Purcell 2010).

\section{RESULTS}

\section{Holothurians of the Cocos (Keeling) Islands}

Fourteen species of holothurians belonging to 7 genera were recorded on the transects (Table 1), with 4 additional species identified outside the surveyed transects. A total of 20556 holothurians were identified and counted, with an average density of 3252 individuals $\mathrm{ha}^{-1}, 97 \%$ of these are considered of low commercial value. The most abundant species was Holothuria atra, which had a mean density of 2983 individuals $\mathrm{ha}^{-1}( \pm 455 \mathrm{SE})$. Of the 14 species recorded during the survey, only 4 further species had relatively high abundances, albeit significantly lower than $H$. atra. Holothuria fuscopunctata was the second most abundant species, followed by Synapta

Table 1. Species, abundance and commercial value of holothurians surveyed at the Cocos (Keeling) Islands. Commercial values of holothurian species are from Purcell (2010). ${ }^{*}$ Species present at the survey sites but outside the area encompassed by the $100 \times 4 \mathrm{~m}$ transect. Abbreviations of species names in parentheses

\begin{tabular}{|c|c|c|c|c|}
\hline Species name & Common name & Commercial value & Mean no. individuals $\left(\mathrm{ha}^{-1}\right)$ & $\mathrm{SE}$ \\
\hline Actinopyga mauritiana (KUY) & Surf redfish & Medium & 3.6 & 1.6 \\
\hline Actinopyga miliaris (KUQ) & Hairy blackfish & Medium & 0.63 & 0.5 \\
\hline Bohadschia argus (KUW) & Leopardfish & Low & 7.4 & 2.5 \\
\hline Chiridota rigida (CRI) & & Unknown & 0.16 & 0.2 \\
\hline Holothuria atra (HFA) & Lolly fish & Low & 2983 & 455.4 \\
\hline Holothuria coluber (HHW) & Snake fish & Low & 0.16 & 0.2 \\
\hline Holothuria edulis (HFE) & Pink fish & Low & 53.6 & 17.1 \\
\hline Holothuria fuscopunctata (HOZ) & Elephant trunkfish & Low & 100.2 & 32.7 \\
\hline Holothuria fuscogilva (HFN) & White teatfish & High & 0.32 & 0.2 \\
\hline Pearsonothuria graeffei (EHV) & Flowerfish & Low & 1.1 & 0.8 \\
\hline Stichopus chloronotus (JCC) & Greenfish & Low & 36.2 & 11.0 \\
\hline Stichopus herrmanni (JCV) & Curryfish & Medium & 0.63 & 0.3 \\
\hline Thelenota ananas (TFQ) & Prickly redfish & Medium & 0.63 & 32.6 \\
\hline Synapta maculata (RSF) & Spotted sea cucumber & Unknown & 64.4 & 0.3 \\
\hline Actinopyga echinites* & Deep water redfish & Medium & & \\
\hline Bohadschia marmorata* & Chalkfish & Low & & \\
\hline Holothuria scabra* & Sandfish & High & & \\
\hline Holothuria whitmaei* & Black teatfish & High & & \\
\hline
\end{tabular}


maculata, Holothuria edulis, and Stichopus chloronotus. The remaining holothurian species recorded during the survey had sporadic distributions and low abundances. No holothurians were observed at 15 of the 79 sites surveyed (Fig. 1).
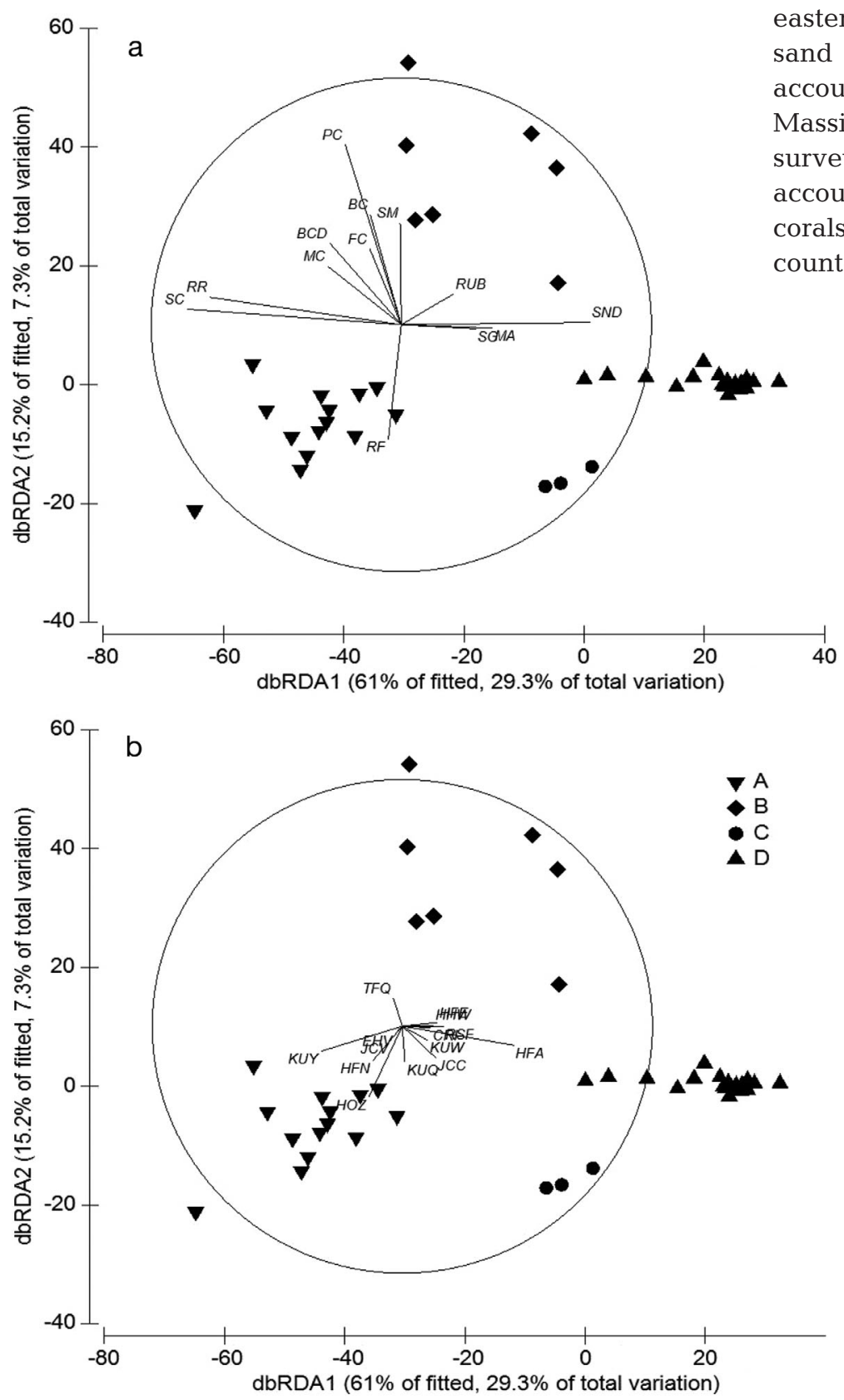

Fig. 2. (a) Distance-based redundancy analysis (dbRDA) demonstrating the distributions of habitats by nominal group (A to $D_{\text {; }}$ see 'Results'). Habitats are: sand (SND), rubble (RUB), seagrass (SG), macroalgae (MA), massive coral (MC), submassive coral (SM), plate coral (PC), foliose coral (FC), soft coral (SC), branching coral (BC), branching coral dead (BCD), reef flat (RF) and relict reef (RR). (b) dbRDA demonstrating the distributions of species by nominal group (A to D). For species abbreviations see Table 1

\section{Habitats of the Cocos (Keeling) Islands}

The fine-scale habitat data were collected at the scale of transects and used for modelling habitat associations. Within the lagoon the primary habitat is sand, with seagrass beds mainly occurring along the eastern and southern sides of the lagoon. In fact, sand was found at $76 \%$ of the sites surveyed and accounted for approximately $31 \%$ of the habitat. Massive and branching corals were also common, surveyed at 62 and $56 \%$ of the sites, respectively, but accounting for only 8 and $6.5 \%$ of the cover. Soft corals were less common ( $42 \%$ of sites) and accounted for $11.5 \%$ of the cover. Relic reef $(13.5 \%)$ and reef flats $(11.1 \%)$ were the other major habitats with respect to cover, although their distribution was less common (48.1 and $11.4 \%$, respectively).

\section{Habitat preferences of holothurian species}

The distance-based linear regression model indicated strong relationships between holothurian assemblages and habitat variables. The most parsimonious model contained 8 of the 13 habitat variables and explained a total of $48 \%$ of the variation in holothurians, with no significant colinearity among the habitat variables. The first dbRDA axis accounted for $29.3 \%$ of the total variation in the holothurian assemblage and distinguished sites dominated by soft corals and relic reefs from soft bottom communities. The second dbRDA axis accounted for $7.3 \%$ of the variation in the holothurian assemblage and largely discriminated living corals from reef flats (Fig. 2a).

Only 4 holothurian species were strongly correlated with the dbRDA axes. Holothuria atra was positively correlated with Axis 1, indicating it was positively associated with sand and negatively associated with relic reef and soft corals. Axis 2 indicated $H$. atra was also positively associated with reef flats, but to a lesser extent. Actinopyga mauritiana (surf redfish) was negatively correlated with Axis 1, indicating a positive association with relic reefs and soft corals, while the positive correlations of $H$. fuscopunctata and Stichopus chloronotus with Axis 2 indicated that they are associated with reef flats.

Sites were then qualitatively assigned to 4 groups based on the distribution of the sites 
Table 2. Average percentage cover of habitat types across the groups. Grouping according to nominal group (see 'Results')

\begin{tabular}{|c|c|c|c|c|c|c|c|c|c|c|c|c|c|}
\hline Site & $\mathrm{n}$ & $\begin{array}{c}\text { Soft } \\
\text { coral }\end{array}$ & $\begin{array}{c}\text { Foliose } \\
\text { coral }\end{array}$ & $\begin{array}{l}\text { Plate } \\
\text { coral }\end{array}$ & $\begin{array}{c}\text { Relic } \\
\text { reef }\end{array}$ & $\begin{array}{l}\text { Reef } \\
\text { flat }\end{array}$ & $\begin{array}{l}\text { Branching } \\
\text { coral }\end{array}$ & Massive & $\begin{array}{c}\text { Branching } \\
\text { dead }\end{array}$ & Sand & Rubble & $\begin{array}{l}\text { Sea- } \\
\text { grass }\end{array}$ & $\begin{array}{c}\text { Macro- } \\
\text { algae }\end{array}$ \\
\hline A & 14 & 36.5 & 0 & 0.2 & 43.3 & 0 & 4.2 & 11.1 & 0.3 & 3.2 & 1.4 & 0 & 0 \\
\hline B & 7 & 17.6 & 15.8 & 4.7 & 18.1 & 0 & 21.5 & 9.2 & 0.9 & 7 & 4.5 & 0 & 0.5 \\
\hline $\mathrm{C}$ & 9 & 0.3 & 0 & 0 & 0 & 97.7 & 0 & 0 & 0 & 1.9 & 0 & 0 & 0 \\
\hline $\mathrm{D}$ & 34 & 1.1 & 0 & 0 & 3.4 & 0 & 2.5 & 5.6 & 0 & 61.8 & 4.5 & 6.8 & 14.1 \\
\hline None & 15 & 15.7 & 0.4 & 2.4 & 13.8 & 0 & 14.9 & 15.2 & 1.5 & 16.9 & 0.6 & 11.8 & 6.7 \\
\hline
\end{tabular}

along the first 2 axes of the dbRDA (Fig. 2). Group A ( $\mathrm{n}=14$ ) included sites strongly associated with soft coral and relic reefs (Table 2). These sites were moderately similar in terms of the holothurians present (similarity $=22.0$ ) and were characterised by low mean abundance of Holothuria fuscopunctata (Table 3). The habitats of Group B sites ( $\mathrm{n}=7$ ) were characterised by a wide range of corals (Table 2). In terms of holothurians, they were depauperate, with the lowest levels of abundance and diversity (Table 3): each site appeared to have low numbers of different species, resulting in a low level of similarity (similarity $=17.3)$. Group $\mathrm{C}$ sites $(\mathrm{n}=9)$ were dominated by reef flat habitat (Table 2). These sites were relatively similar (similarity $=52.5$ ) and supported, on average, high abundances of holothurians, the second highest abundances of $H$. atra, and the highest mean abundances of $H$. fuscopunctata and Stichopus chloronutus. These sites also had the highest levels of holothurian diversity (Table 3). Individuals in Group D ( $\mathrm{n}=34$ ) were not associated with hard bottom reef flats or soft corals and relict reef (Fig. 2). Rather, they were characterised by sand and macroalgae (Table 2). They had the highest level of similarity (similarity $=59.7$ ) and the highest abundance of $H$. atra (Table 3). They were also the only sites with Synapta maculata and had the highest abundances of $H$. edulis. $H$. fuscopunctata, the second most abundant holothurian in the lagoon was almost absent from the Group D sites (Table 3).

Standing abundance weighted for mean density of holothurians per broad-scale habitat type and the areal extent of each habitat was estimated at 44.8 million holothurians (with 95\% lower and upper confidence limits of 9.9 and 63.3 million) or approximately 3340 individuals ha $^{-1}$ (Table 4). Of these $96.6 \%$ are considered to be of low economic value, mostly Holothuria atra, an additional $3.3 \%$ are of unknown value, while only $0.12 \%$ are of medium or high value. The most important habitat for holothurians in the lagoon was coral and algal flats; this habitat was relatively common (13.2\%) and supported the highest abundances of holothurians, i.e. $39 \%$ of the standing abundance of holothurians (Table 4). Prograding sand sheets comprise only $6.5 \%$ of the area, but had the second highest density of holothurians and supported $16 \%$ of all holothurians (Table 4 ). Species of high economic value are found in only 2 habitats outside the lagoon; outer reef coral terrace and coral and algal flats associated with the reef flat. The outer reef coral terrace is relatively extensive $(16.3 \%)$, but has low densities of holothurians, including economically important species. The coral and algal flats associated with the reef flat are moderately extensive $(7.2 \%$ of the atoll), with higher densities of holothurians, but economically important species are an order of magnitude lower in abundance than on the outer reef terrace.

\section{DISCUSSION}

The current study identified a total of 14 species of holothurians at the sites surveyed, with a further 4 species identified outside the survey sites. A previous survey of holothurians at Cocos (Keeling) Islands identified 34 species of holothurians (Marsh 1994). However, it is difficult to compare the results of the 2 studies as Marsh (1994) focused on identifying species diversity by searching discrete areas, while the current study focused on quantifying the abundance

Table 3. Mean abundances (individuals $\mathrm{ha}^{-1}$ ) of the 5 most abundant holothurians by group

\begin{tabular}{|lccccc|}
\hline Group & $\begin{array}{c}\text { Holothuria } \\
\text { atra }\end{array}$ & $\begin{array}{c}\text { Holothuria } \\
\text { fuscopunctata }\end{array}$ & $\begin{array}{c}\text { Synapta } \\
\text { maculata }\end{array}$ & $\begin{array}{c}\text { Holothuria } \\
\text { edulis }\end{array}$ & $\begin{array}{c}\text { Stichopus } \\
\text { chloronutus }\end{array}$ \\
\hline A & 0.29 & 5.29 & 0.00 & 0.14 & 0.04 \\
B & 0.57 & 0.00 & 0.00 & 0.07 & 0.50 \\
C & 112.89 & 26.83 & 0.00 & 0.06 & 4.78 \\
D & 247.16 & 0.03 & 5.99 & 4.90 & 1.99 \\
\hline
\end{tabular}




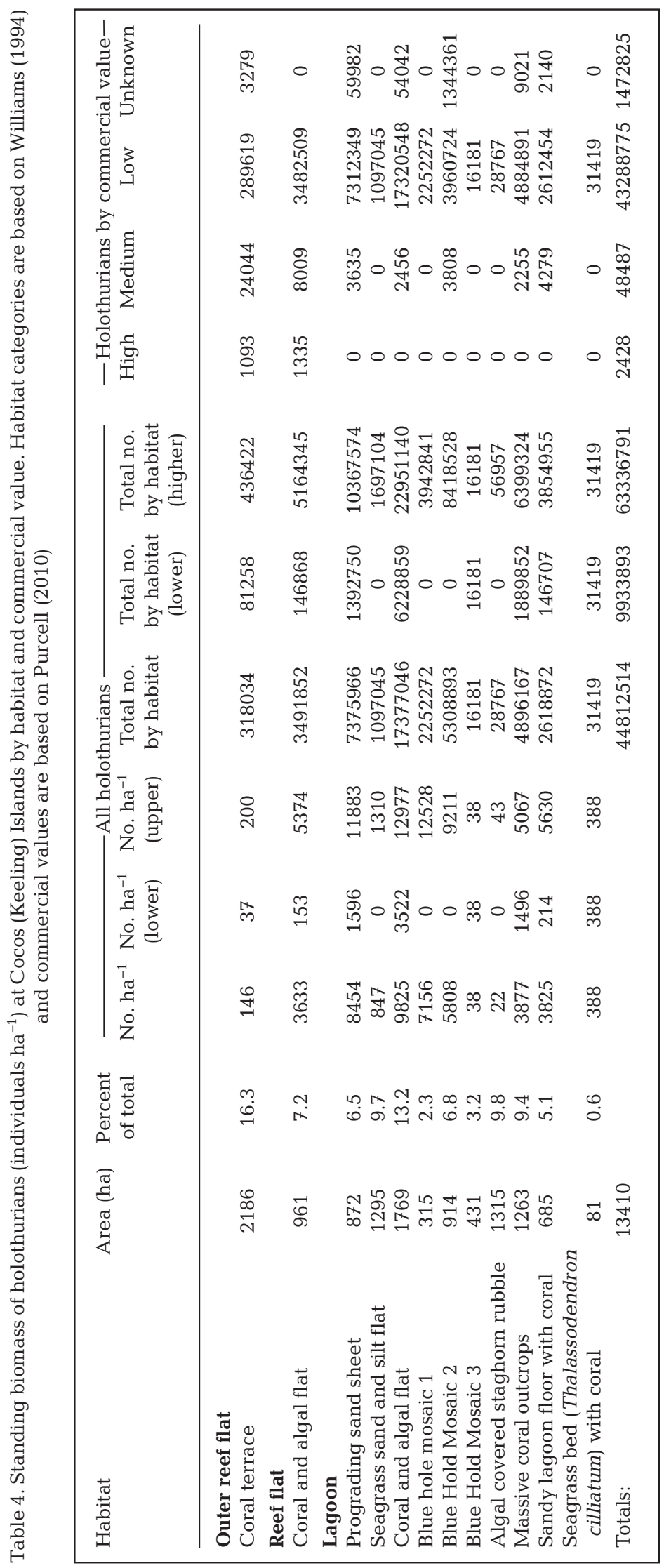

and distribution of holothurians across the entire atoll using a spatially stratified survey. While Marsh (1994) conducted a qualitative survey, some observations on the abundance of 9 species were made. Marsh (1994) states that Holothuria atra was the most common species; H. nobilis and Thelenota ananas were the most valuable species, but they were not abundant; Actinopyga echinites and A. mauritiana were common to abundant on reef flats; and Bohadschia marmorata, $H$. scabra and $B$. argus were also common. With the exception of $A$. mauritiana, which was not found in the current survey, these statements are reflected in the results of our survey. In contrast, Hender et al. (2001) identified only 8 species of holothurians at Cocos (Keeling) Islands. The higher number of species identified in the current survey, compared to Hender et al. (2001), may reflect the increased spatial coverage of the present survey, which included reef slopes and reef flat habitats.

In the current study, an average total density of 3252 individuals ha ${ }^{-1}$ was recorded. This is approximately half the density recorded by Hender et al. (2001) of 7512 individuals $\mathrm{ha}^{-1}$. The difference in the density of holothurians between the 2 surveys may be due to the habitats surveyed or survey techniques used. Hender et al. (2001) did not sample the reef flats or crests, which may have resulted in overestimating the abundance of holothurians across the atoll. Similarly, scaling up observations of densities from relatively small areas (i.e. quadrats) to densities on larger scales (e.g. individuals ha ${ }^{-1}$ ) may result in overestimations (Andrew \& Mapstone 1987). As the 2 studies used different sampling techniques - Hender et al. (2001) surveyed holothurians species within $2 \times 2 \mathrm{~m}$ quadrats, while the current study used $100 \times$ $4 \mathrm{~m}$ transects - this may also explain some of the variation. Previous studies have also suggested that cryptic or sheltering behaviour is common in holothurians and may lead to biases in abundance estimates (Hammond et al. 1985, Shiell \& Knott 2008). However, as the current study used similar methods (surfaceor diver-based observations) and surveys were conducted throughout the day, the contrasts in density estimates may also reflect the natural variability in the abundance of holothurians at the Cocos (Keeling) Islands. 
Observed densities in the present study of several holothurian species are higher than those in other locations, i.e. Holothuria atra (Skewes et al. 2002, PNG; Aumeeruddy et al. 2005, Seychelles; Dissanayake \& Stefansson 2010, Sri Lanka), Actinopyga mauritiana (Skewes et al. 2002, PNG; NFA 2007, PNG) and $H$. fuscopunctata (Skewes et al. 2002, PNG; Aumeeruddy et al. 2005, Seychelles; NFA 2007, PNG). However, several species recorded in the current survey had lower densities than those observed in other studies, i.e. H. whitmaei (Skewes et al. 2002, PNG; NFA 2007, PNG), A. echinites (Aumeeruddy et al. 2005; Dissanayake \& Stefansson 2010, Sri Lanka). Despite these differences in densities, given the current lack of subsistence or commercial fisheries targeting holothurians, the holothurian population at Cocos (Keeling) Islands represents an unexploited stock in its natural state.

The distribution and abundance of holothurians at the Cocos (Keeling) Islands is closely linked with the distribution and nature of benthic habitats. Previous authors have reported that holothurians exhibit distinct habitat preferences (Uthicke \& Benzie 2000, Shiell 2004, Conand 2008, Kinch et al. 2008). For example, populations of Holothuria nobilis in northern Western Australia showed distinct preferences for outer reef zones, specifically, the reef flat and reef crest (Shiell 2004). Other studies have suggested that $H$. atra has no recognizable pattern of distribution (Massin \& Doumen 1986, Shiell 2004); however, in the present study $H$. atra was primarily found in sand-dominated habitats. These habitats are common, particularly in the lagoon, and, on average, account for $31 \%$ of the habitat at Cocos (Keeling) Islands. The distribution of this species may also be due to its relatively unselective feeding habits (Uthicke \& Karez 1999). In contrast, H. fuscopunctata and Stichopus chloronotus both displayed a positive relationship with reef flats, with $H$. fuscopunctata occurring primarily on the outer reef slopes and only a few individuals recorded within the lagoon. On the other hand, S. chloronotus occurs throughout the central region of the atoll. Previous studies have suggested that Stichopus spp. appear to select particular sediment types (Uthicke \& Karez 1999); therefore, the patchy distribution of S. chloronotus within the lagoon may be a result of its feeding preferences. In the current study there is a distinct link between habitat variables and the abundance and distribution of holothurians; however, other factors may well be contributing to the remaining variation not explained by habitat classification. Environmental drivers such as sediment grain size and organic content, water depth and flow may also be important drivers of holothurian distributions (Conand \& Chardy 1985, Hammond et al. 1985, Uthicke \& Karez 1999). Similarly, larval dispersion (Massin \& Doumen 1986) recruitment (Purcell 2010) and behaviour (Shiell \& Knott 2008) may also affect distribution patterns.

Despite observed patterns between holothurians and habitat, their ecology and population dynamics remain poorly understood and knowledge of the effects of reduced holothurian densities on the ecology of reefs and reef flats is limited. In a rare ecological study, abundance of the sea star Proteaster nodosus increased following a decrease in holothurian numbers due to overfishing (Tomascki et al. 1997). Ecologically, holothurians are an important component of soft bottom communities (Conand 2008) and play an important role in benthic recycling (Uthicke \& Klumpp 1998, Uthicke 2001, Mangion et al. 2004). Therefore, decreases in holothurian numbers through overfishing may have a major impact on reef ecology and resilience (Uthicke 2004, Uthicke et al. 2009, Friedman et al. 2010).

Many holothurian fisheries, both tropical and temperate, are in varying stages of overexploitation (Conand 2008, Friedman et al. 2010, Purcell 2010), with limited or no scientific data available on stock size before or after fishing. Holothurians display particular characteristics that make them vulnerable to recruitment overfishing, including sessile, shallow water and patchy distributions. In addition, many holothurian fisheries are based in developing countries, where local communities are dependent on the income but lack the resources to manage these relatively dynamic fisheries (Kinch et al. 2008, Friedman et al. 2010). However, a significant number of holothurian species in countries such as Australia are also overexploited (Kinch et al. 2008). The sandfish Holothuria scabra fishery on Warrior Reef, Torres Strait, was closed in 1998 following several years of high fishing mortality (Skewes et al. 1998). The black teatfish $H$. whitmaei, formerly $H$. nobilis) fishery off the east coast of Queensland was closed in 1999 due to overfishing, with stocks on fished reefs reduced to $<25 \%$ of that observed in areas closed to fishing (Uthicke \& Benzie 2000). The sandfish fishery on the east coast of Australia (Hervey Bay) was also closed in 2000 due to a severe stock decline. Fishery-independent surveys have occurred since the closures of these fisheries, and to date there is little evidence of recovery (Skewes et al. 1999, Uthicke et al. 2004b). The conclusion from these Australian fisheries suggests that holothurian abundance can be severely impacted by overfishing and that recovery following such exploitation may be slow. 
The Australian holothurian populations at the Cocos (Keeling) Islands are also at risk of overexploitation should a fishery be established. Currently, species of low commercial value $(96 \%$ of total abundance) such as Holothuria atra are dominant, while species with high commercial value (e.g. $H$. fuscogilva) are relatively rare $(<0.1 \%$ total abundance). As the population is unfished, the low abundance, particularly of high-value species, represents natural levels; however, there are few (if any) studies of unfished populations for comparison. High-value species, like $H$. fuscogilva and $H$. whitmaei with their low abundances, patchy distributions and prevalence in easily accessible locations (e.g. reef flats), would be highly vulnerable to overexploitation. This is further compounded by the isolation of the atoll, which may result in limited larval input from nonatoll holothurian populations (Hender et al. 2001, Uthicke et al. 2004a). As many of the high-value species are not known to reproduce asexually, a decrease in population numbers of these species from fishing activities may inhibit the population's ability to be self-sustaining (Uthicke et al. 2009). Ultimately this could lead to localised extinction of these species at the Cocos (Keeling) Islands, which could have flow-on effects on the functioning and resilience of the atoll's reef communities.

Acknowledgements. This work was funded by the Attorney General's Office, Australian Government, which provided salaries for L.M.B. and S.N.E., as well as funding for project logistics. P.L. was supported by the Natural Sciences and Engineering Research Council of Canada and as a Visiting Professor at the University of Western Australia. We are grateful to Parks Australia Cocos (Keeling) Islands, in particular Ismail Macrae, Mohammad-Said Chongkin and Chris Boland for their advice and assistance in the field. We thank Dave Abdo for his contribution to earlier versions of this manuscript, Fiona Webster and Dovid Clarke for their invaluable assistance in the field, and Dieter Gerhard from Cocos Dive. We also thank the residents of the Cocos (Keeling) Islands who provided advice and assistance and several colleagues whose comments greatly improved this manuscript.

\section{LITERATURE CITED}

Anderson SC, Mills Flemming J, Watson R, Lotze HK (2010) Serial exploitation of global sea cucumber fisheries. Fish Fish 12:1-23

Andrew NL, Mapstone BD (1987) Sampling and the description of spatial pattern in marine ecology. Oceanogr Mar Biol Annu Rev 25:39-90

Aumeeruddy R, Skewes T, Dorizo J, Carocci F, Coeur de lion F, Harris A, Henriette C, Cedars M (2005) Resource assessment and management of the Seychelles sea cucumber fishery. FAO Project Number: TCP/Seychelles/ 2902(A), FAO, Rome
Bellchambers LM, Evans S, Meeuwig J (2010) Abundance and size of western rock lobster (Panulirus cygnus) as a function of benthic habitat: implications for ecosystembased fisheries management. Mar Freshw Res 61: 279-287

Berry PF (1989) Survey of the marine fauna of Cocos (Keeling) Islands, Indian Ocean. Western Australian Museum, Perth

Bunce P (1988) The Cocos (Keeling) Islands. Australian Atolls in the Indian Ocean. The Jacaranda Press, Milton

Choo PS (2008) Population status, fisheries and trade of sea cucumbers in Asia. In: Toral-Granda V, Lovatelli A, Vasconcellos M (eds) Sea cucumbers: a global review of fisheries and trade. FAO Fish Aqua Tech Pap 516, FAO, Rome, p 81-119

Clarke KR, Warwick RN (2001) Changes in marine communities: an approach to statistical analysis and interpretation, 2nd edn. PRIMER-E Ltd, Plymouth

Conand C (2004) Present status of world bêche de mer resources and utilization: an international overview. In: Lovatelli A, Conand C, Purcell S, Uthicke S, Hamel JF, Mercier A (eds) Advances in sea cucumber aquaculture and management. FAO Fish Tech Pap 463, FAO, Rome, p 13-24

Conand C (2008) Population status, fisheries and trade of sea cucumbers in Africa and the Indian Ocean. In: ToralGranda V, Lovatelli A, Vasconcellos M (eds) Sea cucumbers: a global review of fisheries and trade. FAO Fish Aqua Tech Pap 516, FAO, Rome, p 143-193

Conand C, Byrne M (1993) A review of recent developments in the world sea cucumber fisheries. Mar Fish Rev 55: $1-13$

Conand C, Chardy P (1985) Are the Aspidochirote holothurians of the New Caledonia lagoon good indicators of the reefal features? In: Delesalle B, Galzin R, Salvat B (eds) Proc 5th Int Coral Reef Congr, Vol 5. Antenne Museum-EPHE, Moorea, Tahiti, p 291-296

> Dissanayake DCT, Stefansson G (2010) Abundance and distribution of commercial sea cucumber species in the coastal waters of Sri Lanka. Aquat Living Resour 23: 303-313

Freeman S, Rogers SI (2003) A new analytical approach to the characterisation of macro-benthic habitats: linking species to the environment. Estuar Coast Shelf Sci 56: 749-764

Friedman K, Eriksson H, Tardy E, Pakoa K (2010) Management of sea cucumber stocks: patterns of vulnerability and recovery of sea cucumber stocks impacted by fishing. Fish Fish 12:75-93

Gibson-Hill CA (1946) Boats and fishing on the Cocos (Keeling) Islands. J R Anthropol Inst 76:13-23

Hammond LS, Birtles RA, Reichelt RE (1985) Holothuroid assemblages on coral reefs across the central section of the Great Barrier Reef. In: Delesalle B, Galzin R, Salvat B (eds) Proc 5th Int Coral Reef Congr, Vol 5. Antenne Museum-EPHE, Moorea, Tahiti, p 285-290

Hender J, McDonald CA, Gilligan JJ (2001) Baseline survey of marine environments and stock size estimates of marine resources of the South Cocos (Keeling) atoll (0-15 m), eastern Indian Ocean. Marine Resources of the Cocos Atoll, Indian Ocean. Fisheries Resources Research Fund, Canberra

Kinch J, Purcell S, Uthicke S, Friedman K (2008) Population status, fisheries and trade of sea cucumbers in the western Central Pacific. In: Toral-Granda V, Lovatelli A, 
Vasconcellos M (eds) Sea cucumbers: a global review of fisheries and trade. FAO Fish Tech Pap 516, FAO, Rome, p 7-56

Legendre P, Anderson MJ (1999) Distance-based redundancy analysis: testing multispecies responses in multifactorial ecological experiments. Ecol Monogr 69:1-24

Lincoln-Smith MP, Underwood AJ, Smith AK, Hawes PMH and others (1993) A study of the impact of harvesting marine invertebrate and fish on the marine ecosystems of Cocos (Keeling) Islands, Indian Ocean. The Institute of Marine Ecology, The University of Sydney

Lovatelli A, Conand C, Purcell S, Uthicke S, Hamel JF, Mercier A (2004) Advances in sea cucumber aquaculture and management. FAO Fish Tech Pap 463, FAO, Rome

Mangion P, Taddei D, Frouin P, Conand C (2004) Feeding rate and impact of sediment reworking by two deposit feeders Holothuria leucospilota and Holothuria atra on a fringing reef (Reunion Island, Indian Ocean). In: Heinzeller T, Nebelsick JH (eds) Echinoderms: München. Taylor and Francis, London, p 311-317

Marsh LM (1994) Echinoderms of the Cocos (Keeling) Islands. In: Woodroffe CD (ed) Atoll research bulletin: ecology and geomorphology of the Cocos (Keeling) Islands. National Museum of Natural History, Smithsonian Institution, Washington, DC

Massin C, Doumen C (1986) Distribution and feeding of epibenthic holothuroids on the reef flat of Laing Island (Papua New Guinea). Mar Ecol Prog Ser 31:185-195

McArdle BH, Anderson MJ (2001) Fitting multivariate models to community data: a comment on distance-based redundancy analysis. Ecology 82:290-297

Mcllgorm A, Lindner B, Kinch J (2007) A sea cucumber fisheries management project in PNG: a project feasibility review to ACIAR. Australian Centre for International Agricultural Research, Canberra

NFA (National Fisheries Authority) (2007) Sea cucumber survey: New Ireland Province. National Fisheries Authority and the Coastal Management and Development Project, Kavieng

Purcell SW (2010) Sea cucumber fisheries. In: Lovatelli A, Vascancellos M, Yimin Y (eds) Managing sea cucumber fisheries with an ecosystem approach. FAO Fish Tech Pap 520, FAO, Rome, p 9-18

Shiell GR (2004) Density of Holothuria nobilis and distribution patterns of common holothurians on coral reefs of northwestern Australia. In: Lovatelli A, Conand C, Purcell S, Uthicke S, Hamel J, Mercier A (eds) Advances in sea cucumber aquaculture and management. FAO Fish Tech Pap 463, FAO, Rome, p 231-237

Shiell GR, Knott B (2008) Diurnal observations of sheltering behaviour in the coral reef sea cucumber Holothuria whitmaei. Fish Res 91:112-117

Skewes TD, Burridge CM, Hill B (1998) Survey of Holothuria scabra (sandfish) on Warrior Reef, Torres Strait. Report to Queensland fisheries management authority, Thursday Island, CSIRO Marine Research, Cleveland

Editorial responsibility: Hans Heinrich Janssen, Oldendorf/Luhe, Germany
Skewes TD, Dennis DM, Jacobs DR, Gordon SR and others (1999) Survey and stock estimates of the shallow reef (0-15 $\mathrm{m}$ deep) and shoal area (15-50 $\mathrm{m}$ deep) marine resources and habitat mapping within the Timor Sea MOU74 Box, Vol 1, Stock estimates and stock status. CSIRO, Clayton South

Skewes TD, Kinch J, Polon PK, Dennis DM and others (2002) Research for sustainable use of bêche de mer resources in Milne Bay province, Papua New Guinea. CSIRO, Cleveland

Tomascki T, Mah AJ, Nontji A, Moosa MK (1997) The ecology of Indonesian seas, Part II. Periplus, Singapore

Toral-Granda V (2006) The biological and trade status of sea cucumbers in the families Holothuriidae and Stichopodidae. Proceedings of the 22nd meeting of the animals committee, Lima (Peru). AC22 Doc. 16, CITES, www. cites.org

Uthicke S (1999) Sediment bioturbation and impact of feeding activity of Holothuria (Halodeima) atra and Stichopus chloronotus, two sediment feeding holothurians, at Lizard Island, Great Barrier Reef. Bull Mar Sci 64:129-141

> Uthicke S (2001) Nutrient regeneration by abundant coral reef holothurians. J Exp Mar Biol Ecol 265:153-170

Uthicke S (2004) Overfishing of holothurians: lessons from the Great Barrier Reef. In: Lovatelli A, Conand C, Purcell S, Uthicke S, Hamel JF, Mercier A (eds) Advances in sea cucumber aquaculture and management. FAO Fish Tech Pap 463, FAO, Rome, p 163-172

Uthicke S, Benzie JAH (2000) The effect of beche-de-mer fishing on densities and size structure of Holothuria nobilis (Echinodermata: Holothurioidea) populations on the Great Barrier Reef. Coral Reefs 19:271-276

Uthicke S, Karez R (1999) Sediment patch selectivity in tropical sea cucumbers (Holothurioidea: Aspidochirotida) analysed with multiple choice experiments. J Exp Mar Biol Ecol 236:69-87

Uthicke S, Klumpp DW (1998) Microphytobenthos community production at a near-shore coral reef: seasonal variation and response to ammonium recycled by holothurians. Mar Ecol Prog Ser 169:1-11

Uthicke S, O'Hara TD, Byrne M (2004a) Species composition and molecular phylogeny of Indo-Pacific teatfish (Echinodermata: Holothuroidea) beche-de-mer fishery. Mar Freshw Res 55:837-848

Uthicke S, Welch D, Benzie JAH (2004b) Slow growth and lack of recovery in overfished holothurians on the Great Barrier Reef: evidence from DNA fingerprints and repeated large-scale surveys. Conserv Biol 18:1395-1404

Uthicke S, Schaffelke B, Byrne M (2009) A boom-bust phylum? Ecological and evolutionary consequences of density variations in echinoderms. Ecol Monogr 79:3-24

Williams DG (1994) Marine habitats of the Cocos (Keeling) Islands. In: Woodroffe CD (ed) Atoll research bulletin: ecology and geomorphology of the Cocos (Keeling) Islands. National Museum of Natural History, Smithsonian Institution, Washington, DC

Submitted: March 16, 2011; Accepted: October 4, 2011 Proofs received from author(s): November 11, 2011 